\title{
Procyanidins in fruit from Sour cherry (Prunus cerasus) differ strongly in chainlength from those in Laurel cherry (Prunus lauracerasus) and Cornelian cherry (Cornus mas)
}

\author{
Esra Capanoglu ${ }^{\mathrm{a}}$, Dilek Boyacioglu ${ }^{\mathrm{a}}$, Ric C.H. de Vos ${ }^{\mathrm{b}, \mathrm{c}}$, Robert D. Hall ${ }^{\mathrm{b}, \mathrm{c}}$ and Jules Beekwilder ${ }^{\mathrm{b}, *}$ \\ ${ }^{a}$ Faculty of Chemical and Metallurgical Engineering, Food Engineering Department, Istanbul Technical University, \\ Maslak, Istanbul, Turkey \\ ${ }^{\mathrm{b}}$ Plant Research International, Wageningen UR, BU Bioscience, Wageningen, The Netherlands \\ ${ }^{\mathrm{c}}$ Centre for BioSystems Genomics, Wageningen, The Netherlands
}

Received 4 October 2010; accepted 25 November 2010

\begin{abstract}
Sour cherry (Prunus cerasus), Laurel cherry (Prunus lauracerasus), and Cornelian cherry (Cornus mas) fruits are widely used in Turkey, both as food and as traditional medicines. The phytochemical composition and antioxidant capacities of these three cherry types were compared. Fruit flesh was evaluated for procyanidin concentration, subunit composition and degree of polymerization, for anthocyanin composition and for total antioxidant capacity, total phenolic content and total flavonoid content. High concentrations (up to $1 \mathrm{~g}$ per $100 \mathrm{~g}$ dry weight) of long-chain procyanidins were found in Laurel cherry, whereas concentrations of procyanidins in Cornelian cherry were 25 times lower. Surprisingly, Sour cherry (0.3 g/100 g DW) had a dramatically different procyanidin profile which was dominated by short polymers, with an average chain length of 4 monomer units. This is of particular interest since short-chain procyanidins have recently been suggested to play a role in the prevention of coronary heart disease.
\end{abstract}

Keywords: Sour cherry, Laurel cherry, Cornelian cherry, procyanidins, anthocyanins

\section{Introduction}

Traditionally, a large diversity of fruit is grown in Turkey for both food and non-food applications. Among these fruits, stone fruits and especially cherries are widely consumed. Many different cherry types can be consumed fresh, but they may also be dried, pickled and processed in a variety of ways and consumed e.g. as pekmez (syrup obtained by condensing juices of the fruit must), pestil (a dried form of marmalade), jam, marmalades, fruit juice products and tea infusions $[15,34,40]$. Besides their food uses and their various tastes and flavors, these cherry types have also been used for traditional medicine applications and are known for their positive health effects $[8,30,38]$. In the work

${ }^{*}$ Corresponding author: Jules Beekwilder, Plant Research International, Wageningen UR, BU Bioscience 6700 AA, Wageningen, The Netherlands. Tel.: +31 317 477164; Fax: +31 317 418094; E-mail: jules.beekwilder@wur.nl. 
reported here, attention is focused on the Sour cherry, Laurel cherry, and Cornelian cherry as these are all widely consumed in Turkey both for their attractive taste as well as for their publically-known health-related benefits [17, $67,72]$.

Sour cherry (Prunus cerasus L.), known as vişne in Turkey, is widely consumed as fresh fruit as well as in many processed products such as jams, liqueur, wine and confectionery items. Its most important application is in the form of juice. Sour cherry has the highest production and consumption rates of all fruits in Turkey [22]. Its consumption has been shown to be associated with a reduced risk of cardiovascular disease [8]. Sour cherry extracts have been shown to display dicyclooxygenase inhibition [58], antineurodegenerative activity [38], anti-inflammatory potential [56], and inhibition of human colon cancer cell proliferation [33].

Laurel cherry fruit (Prunus lauracerasus L., L. officinalis), which is also known as taflan or karayemiş, is grown in the eastern Blacksea region of Turkey. Laurel cherries are well known for their high mineral and antioxidant contents $[12,39]$. Both the fruit and the stones are favored as traditional medicines in Turkey and have been used for many years for the treatment of a wide variety of ailments including stomach ulcers, digestive system complaints, bronchitis, eczema, haemorrhoids, and as a diuretic agent [40].

Fruits of the Cornelian cherry (Cornus mas L.) are still harvested from the wild, and have a notably sour taste. The fruits have been applied as food preservatives, but also in traditional Turkish medicine for treatment of gastrointestinal disorders and diarrhea [15]. Cornelian cherry fruits have also been reported to have anti-allergic, anti-microbial, anti-malarial and anti-diabetic activities $[19,31,65,66,70]$.

Regarding their phytochemical composition, cherries are known for their high levels of phenolic antioxidants and in particular, anthocyanins and procyanidins. Both categories of compounds have been particularly associated with health effects, apart from their general antioxidant activity. Cherries are ranked among the richest sources of procyanidins [9]. Procyanidins represent oligomers or polymers of flavan-3-ol units, while anthocyanins are essentially monomeric molecules which carry glycosidic moieties. The degree of procyanidin polymerization, which may vary from two subunits up to several hundred, appears to be relevant for their absorption in the intestinal tract $[20,26,37]$, and is therefore relevant for their general efficacy and their contribution e.g. to cardiovascular health.

Procyanidins have been linked to some of the health-related effects associated with cherry fruits $[17,67,72]$. In vivo and in vitro studies have shown that procyanidins increase nitric oxide synthesis, inhibit platelet activation, stimulate the production of anti-inflammatory cytokines, and inhibit the production of certain proinflammatory cytokines [45, 57, 71]. They limit free radical formation by inhibiting enzymes or chelating metals involved in their generation and lower the rate of low-density lipoprotein (LDL) oxidation [60, 68]. These activities have been associated with reduced risks for coronary heart disease. There is a remarkable correspondence of procyanidin activities to those of Sour cherry juice, as reported from a study on diabetic women, which were given a Sour Cherry juice concentrate [8]. In this study, reduced blood pressure, body weight and LDL cholesterol were reported.

In the present study we have compared the content of bio-active molecules of these three cherry types. The qualitative and quantitative composition of anthocyanins and procyanidins were compared, as well as their overall antioxidant activities, phenolic content and flavonoid content.

\section{Materials and methods}

\subsection{Fruit material}

Replicate samples of Sour cherry and Cornelian cherry were obtained separately from a bazaar in Istanbul. Laurel cherry replicate samples were provided from a local market in Trabzon, Turkey. The stones of the fruit were removed and the de-stoned fruits were snap-frozen in liquid nitrogen after which they were transported in still frozen state to the Netherlands in dry ice. Samples were subsequently ground to a fine powder in liquid nitrogen using a pre-cooled electric grinder. All powder samples were then individually freeze-dried to compensate for the differences in water content, and stored at $-80^{\circ} \mathrm{C}$ until analysis. The water content was generally found to be around $80 \%$ for all three cherry types. 


\subsection{Spectrophotometric assays}

Extracts for spectrophotometric assays for total antioxidant activities, total phenolics, and total flavonoids were prepared as described previously [13].

Total antioxidant activities were evaluated by the ABTS (2,2-azinobis 3-ethylbenzothiazoline-6-sulfonic acid diammonium salt) method [47], the FRAP (Ferric Reducing Antioxidant Power) method [10], and the CUPRAC (Copper Reducing Antioxidant Capacity) method [2, 3]. In all assays, Trolox was used as a reference compound and results were expressed in terms of mM Trolox Equivalent Antioxidant Capacity (TEAC) per $100 \mathrm{~g}$ DW.

The total phenolic content was estimated using the Folin-Ciocalteu reagent [62], using $100 \mu$ l of extract, $900 \mu l$ pure water and $5 \mathrm{ml}$ reagent. For the preparation of a standard curve, $0.10-0.50 \mathrm{mg} / \mathrm{ml}$ gallic acid was used and data were expressed in mg gallic acid equivalents (GAE) per $100 \mathrm{~g}$ dry weight (DW).

Total flavonoid content was determined according to Dewanto et al. [21]. Absorbance of the samples was measured at $510 \mathrm{~nm}$ against a reagent blank. Catechin at concentrations of $0.01-0.25 \mathrm{mg} / \mathrm{ml}$ was used to create a calibration curve and data were expressed in mg catechin equivalents ((+) CE) per $100 \mathrm{~g} \mathrm{DW}$.

\subsection{Anthocyanin analysis}

For the analysis of anthocyanin content, $25( \pm 0.05) \mathrm{mg}$ freeze-dried sample was extracted with $2.0 \mathrm{ml} 75 \%$ methanol in ultrapure water following the procedure described before [11]. Sample extracts were analyzed by HPLCPDA as described before [39]. Briefly, compounds were separated using a Luna C18 column (Phenomenex, USA) in a Waters HPLC system (W600), employing a gradient of $0.1 \%$ formic acid and acetonitrile. Eluting compounds were detected by PDA (Waters 996) detector at $512 \mathrm{~nm}$ for anthocyanins.

\subsection{Procyanidin analysis}

For analysis of procyanidins, terminal units and extension units should be distinguished. Under acidic conditions, procyanidins depolymerize, which results in the release of terminal subunits as flavan-3-ol monomers, while extension subunits are released as electrophilic flavan-3-ol intermediates. The electrophilic intermediates can be trapped by

a nucleophilic reagent (in this case phloroglucinol), to generate analyzable adducts. Thus, the concentration of terminal subunits and extension units can be determined, and the degree of polymerization can be determined. In this study, procyanidins were evaluated using the phloroglucinol hydrolysis method with slight modifications [35]. To 50 ( \pm 0.05$) \mathrm{mg}$ freeze-dried material, $0.8 \mathrm{ml}$ of solution A $(10 \mathrm{~g} / \mathrm{l}$ Vitamin $\mathrm{C}+50 \mathrm{~g} / \mathrm{l}$ phloroglucinol $)$, and $0.4 \mathrm{ml}$ of solution $\mathrm{B}(0.3 \mathrm{M} \mathrm{HCl}$ diluted in methanol) were added. The phloroglucinol-treated samples were then incubated at $50^{\circ} \mathrm{C}$ for $30 \mathrm{~min}$ for hydrolysis, shaking every $10 \mathrm{~min}$. Lastly, $1.2 \mathrm{ml}$ of $200 \mathrm{mM} \mathrm{Na}$ Acetate was added and the samples were filtered and analyzed by HPLC. For HPLC analysis, the same set-up was used as for the anthocyanins, using a Waters 2475 Fluorescence Detector with excitation at $275 \mathrm{~nm}$ and emission at $310 \mathrm{~nm}$ for the detection of $(+)$ catechin and (-) epicatechin. To determine (+) catechin and (-) epicatechin monomers in the original samples, another $50( \pm 0.05) \mathrm{mg}$ of freeze-dried material was weighed, and $2.4 \mathrm{~mL} 75 \%$ methanol was added for extraction. Free flavan-3-ol monomers $(++)$ catechin and (-) epicatechin) were detected in the unhydrolyzed sample, while the end-positioned flavan-3-ols plus the originally free flavan-3-ols were observed as flavan-3-ols in the phloroglucinoltreated hydrolyzed sample. The non-end positioned flavan-3-ols of procyanidins were observed as phloroglucinol conjugates in the hydrolyzed sample. The Degree of Polymerization (DP) was calculated by the following equation: $\mathrm{DP}=($ end flavan-3-ols plus non-end flavan-3-ols)/(end flavan-3-ols).

\subsection{Statistical analysis}

All analyses were performed with three technical replicates. For Cornelian cherry and Laurel cherry, two samples were individually purchased (biological replicates) and for the Sour cherry three samples (biological replicates) were available. $N=6$ ( 2 biological replicates $\times 3$ technical replicates) samples for Cornelian cherry and Laurel cherry samples, $N=9$ (3 biological replicates $\times 3$ technical replicates) for Sour cherry samples were independently analyzed and the data from all analyses were taken for statistical analyses. The calculated standard deviation (SD) of 
the biological replicates was not different from the SD of the technical replicates. Data were subjected to statistical analysis using SPSS software (version 11.5, SPSS Inc.) for the Analysis of Variance (ANOVA). Duncan's New Multiple Range Test was used to analyze differences between treatments.

\section{Results}

\subsection{Spectrophotometric methods}

The total antioxidant activities of the cherry samples were determined by three different methods (Table 1). All three methods indicated that the Cornelian cherries had three times higher total antioxidant capacity than Sour cherries, while Laurel cherries had an intermediate antioxidant capacity.

The total phenolic content of the different cherries followed the same trend as observed for the antioxidant capacity, but the differences were less pronounced (Table 2). The Cornelian cherry samples showed a total phenolic content which was roughly $50 \%$ higher than both the Laurel cherry and Sour cherry samples.

In contrast, the total flavonoid content values showed a different trend than the other spectrophotometric methods (Table 2). Here, the Laurel cherry showed an almost two-fold higher value, relative to both the Cornelian cherry and the Sour cherry.

\subsection{Anthocyanins}

The absorbance spectra of anthocyanins detected in the cherries analyzed indicated that the compounds mainly consisted of glycosylated forms of cyanidin and, in case of Laurel cherry, also of pelargonidin derivatives (Fig. 1). The dominant compounds were cyanidin-3-O-glucoside and cyanidin-3-O-rutinoside, as was verified using authentic standards. The total quantity of anthocyanins did not differ greatly between the different cherry types (Table 3).

Table 1

Antioxidant capacities of cherry samples ${ }^{\mathrm{a}}$

\begin{tabular}{lcrr}
\hline mmole TEAC/100 g DW & ABTS & CUPRAC & FRAP \\
\hline Sour cherry & $17.8 \pm 1.7 \mathrm{c}$ & $29.7 \pm 1.2 \mathrm{c}$ & $7.6 \pm 0.3 \mathrm{c}$ \\
Laurel cherry & $28.4 \pm 1.4 \mathrm{~b}$ & $46.9 \pm 1.9 \mathrm{~b}$ & $13.3 \pm 0.9 \mathrm{~b}$ \\
Cornelian cherry & $50.8 \pm 2.0 \mathrm{a}$ & $76.3 \pm 3.6 \mathrm{a}$ & $22.3 \pm 0.9 \mathrm{a}$ \\
\hline
\end{tabular}

${ }^{a}$ The values having different letters in columns are significantly different according to Duncan's New Multiple Range Test, $N=6$ for Laurel cherry and Cornelian cherry samples, and $N=9$ for Sour cherry samples $(P<0.05)$.

Table 2

Total flavonoid and total phenolic content of the cherry samples

\begin{tabular}{lcc}
\hline & Total flavonoids $(\mathrm{mg}(+) \mathrm{CE} / 100 \mathrm{~g} \mathrm{DW})$ & Total phenolics $(\mathrm{mg}$ GAE/100 $\mathrm{g} \mathrm{DW})$ \\
\hline Sour cherry & $420.5 \pm 21.1 \mathrm{~b}$ & $3371.1 \pm 134.8 \mathrm{~b}$ \\
Laurel cherry & $952.5 \pm 47.6 \mathrm{a}$ & $3129.2 \pm 125.0 \mathrm{~b}$ \\
Cornelian cherry & $477.3 \pm 22.9 \mathrm{~b}$ & $4918.8 \pm 195.7 \mathrm{a}$ \\
\hline
\end{tabular}

The values having different letters in columns are significantly different according to Duncan's New Multiple Range Test, $N=6$ for Laurel cherry and Cornelian cherry samples, and $N=9$ for Sour cherry samples $(P<0.05)$. 

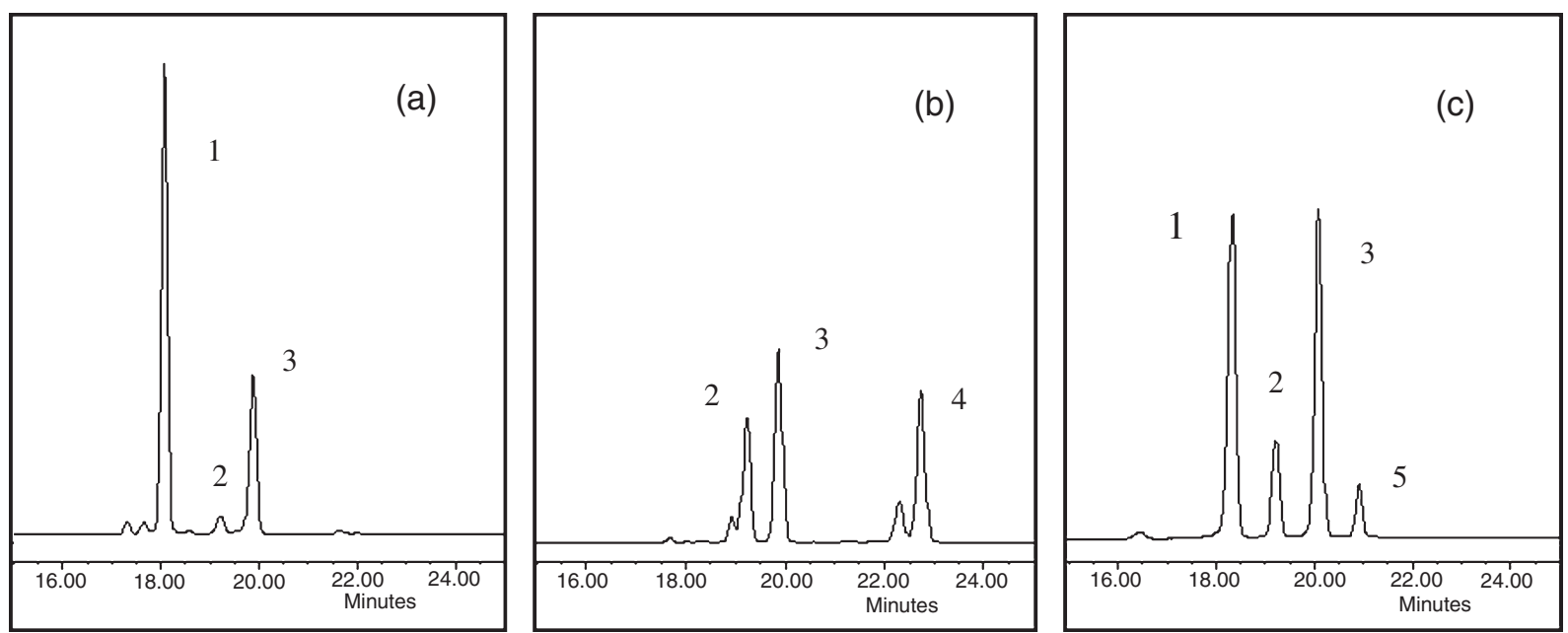

Fig. 1. HPLC profiles, recorded at $512 \mathrm{~nm}$, of aqueous-methanol extracts from (a) Sour cherry, (b) Laurel cherry, (c) Cornelian cherry. Peaks indicated correspond to: (1) cyanidin- glucoside-rutinoside, (2) cyanidin-3-glucoside, (3) cyanidin-3-rutinoside, (4) pelargonidin-3-glucoside, (5) a cyanidin derivative.

Table 3

Content of main anthocyanins in three Turkish cherry types. Levels are in $\mathrm{mg} / 100 \mathrm{~g}$ DW (means $\pm \mathrm{SD}, N=6$ for Laurel cherry and Cornelian cherry samples, and $N=9$ for Sour cherry samples), using cyanidin glucoside (for the cyanidin derivatives) or pelargonidin glucoside as standards. nd: not detectable

\begin{tabular}{lccccc}
\hline & $\begin{array}{c}\text { Cyanidin-glucoside- } \\
\text { rutinoside }\end{array}$ & Cyanidin-3-glucoside & Cyanidin-3-rutinoside & Pelargonidin-3-glucoside & Cyanidin derivative \\
\hline Figure 1 & Peak 1 & Peak 2 & Peak 3 & Peak 4 & Peak 5 \\
Sour cherry & $16.3 \pm 2.0$ & $0.7 \pm 0.1$ & $6.5 \pm 1.4$ & nd & nd \\
Laurel cherry & nd & $4.6 \pm 1.1$ & $6.6 \pm 1.2$ & $11.0 \pm 2.1$ & nd \\
Cornelian cherry & $11.8 \pm 1.5$ & $4.4 \pm 1.1$ & $11.7 \pm 1.9$ & nd & $1.9 \pm 0.3$ \\
\hline
\end{tabular}

\subsection{Procyanidins}

The qualitative and quantitative procyanidin content of the different cherries varied significantly (Table 4). While in Laurel cherries the total flavan-3-ol content (as a sum of (+) catechin and (-) epicatechin concentrations) was $1 \%$ of their dry weight, in Sour cherries it was $0.3 \%$ and in Cornelian cherries only $0.04 \%$. While $(-)$ epicatechin units dominated the procyanidin polymers in all samples, the (+) catechin contribution differed strongly. The Laurel cherry procyanidins consisted of $0.2 \%$ of $(+)$ catechin, while this was $5 \%$ in Sour cherries and $10 \%$ in Cornelian cherries. Remarkably, in Sour cherries the mean degree of polymerization was much lower (10-15-fold) than in the other two fruit types. Apparently, short-chain procyanidins are dominant in Sour cherry fruit.

\section{Discussion}

Cherry fruits are well known for being rich in phenolic compounds and in particular, for their high levels of procyanidins $[9,24]$. In this study we observed a large qualitative and quantitative variation in the procyanidin content of the three types of cherry. Laurel cherries and Sour cherries were found to have a total flavan-3-ol content of $1089 \mathrm{mg} / 100 \mathrm{~g}$ DW and $328 \mathrm{mg} / 100 \mathrm{~g}$ DW, respectively. This corresponds to about $218 \mathrm{mg} / 100 \mathrm{~g} \mathrm{FW}$ and $66 \mathrm{mg} / 100 \mathrm{~g}$ $\mathrm{FW}$, respectively. These levels are in the range of other well-known rich sources of procyanidins, such as grape seeds 
Table 4

Flavan-3-ol contents, in mg per $100 \mathrm{~g} \mathrm{DW}$, and mean degree of procyanidins polymerization in the cherry samples ${ }^{\mathrm{a}}$

\begin{tabular}{lccccc}
\hline & Total $(+)$ catechin & Free (+) catechin & Total (-) epicatechin & Free (-) epicatechin & Mean degree of polymerization ${ }^{\mathrm{b}}$ \\
\hline Sour cherry & $15.4 \pm 0.8 \mathrm{a}$ & $0.14 \pm 0.01 \mathrm{a}$ & $312.5 \pm 15.6 \mathrm{~b}$ & $0.10 \pm 0.02 \mathrm{ab}$ & $3.9 \pm 0.2 \mathrm{c}$ \\
Cornelian cherry & $3.5 \pm 0.1 \mathrm{~b}$ & $0.08 \pm 0.01 \mathrm{~b}$ & $35.5 \pm 4.5 \mathrm{c}$ & $0.01 \pm 0.005 \mathrm{~b}$ & $62.9 \pm 3.1 \mathrm{a}$ \\
Laurel cherry & $2.0 \pm 0.1 \mathrm{~b}$ & $0.10 \pm 0.01 \mathrm{ab}$ & $1087.7 \pm 53.5 \mathrm{a}$ & $0.17 \pm 0.04 \mathrm{a}$ & $45.2 \pm 2.1 \mathrm{~b}$ \\
\hline
\end{tabular}

${ }^{a}$ Values having different letters in columns are significantly different according to Duncan's New Multiple Range Test, $N=6$ for Laurel cherry and Cornelian cherry samples, and $N=9$ for Sour cherry samples $(P<0.05) .{ }^{\mathrm{b}}$ Total bound (epi)catechin units/end units.

$(17-250 \mathrm{mg} / 100 \mathrm{~g})$ [27] and dark chocolate (31-37 mg/100 g) [46], and also correspond to the content of total (+) catechins found in sweet cherries (Prunus dulcis; $117 \mathrm{mg} / \mathrm{kg} \mathrm{FW}$ ) [7].

Antioxidant activity was measured by three different assays. The different standards used to report the antioxidant capacity as well as the wide variations in analytical techniques make comparisons between various studies harder and also raise the question whether apparently conflicting results are associated with non-standardized assay techniques [14]. The differences between test methods might be as a result of the variations in the principle of the antioxidant assay, the radical that is generated, the end-point detection, and the allocated reaction time $[1,4]$. Evaluation of antioxidant capacity of fruits, vegetables, and other plant products cannot be performed accurately by any single method due to the complex nature of phytochemicals present [16]. So, it is highly recommended to apply several test procedures for a full evaluation of antioxidant capacity $[1,4,14]$. In case of the cherry fruits, the three methods used gave consistent results, in that the Cornelian cherry has a very high antioxidant capacity, relative to the other cherries (Table 1), and also the highest level of phenolic compounds (Table 2). In contrast, Cornelian cherries had a much lower content of procyanidins ( $39 \mathrm{mg} / 100 \mathrm{mg}$ DW) then the other two types, and also a lower level of total flavonoids. Therefore phenolic compounds other than flavonoids are probably more prominent in Cornelian cherry fruit.

Contents of flavonoid, anthocyanins and other antioxidants may be influenced by differences in the variety, ripeness of the fruits and the growing conditions. It was reported that sweet cherry cultivars may show pronounced differences in the concentrations of individual phenolic compounds [24]. Likewise, fruit ripeness and seasonal variations may strongly affect concentrations of anthocyanins in particular [7, 24]. It is unclear if such variations also account for procyanidin polymers. According to Kennedy et al. [36], the relative proportion of procyanidin extension units in grape seeds did not vary with maturity, and fruit ripening did not alter the mean degree of polymerization of extracted procyanidins, at least when analyzed intact by HPLC, but decreases by thiolytic degradation. Further research in cherry fruit samples collected during several years will have to be performed to monitor changes in procyanidins concentration and polymer length.

In vitro assays point to strong protective properties of procyanidins regarding oxidative damage, microbial infection, prevention of colon cancer, and prevention of cardiovascular disease [6, 42, 50, 55]. However, the degree of polymerization of procyanidins may be highly influential and determine the relevance of these activities to their therapeutic or profilactic properties $[25,29,59]$. Fruits characterized by a high content of procyanidins with relative high degree of polymerization, i.e. long-chain polymers, such as Laurel cherry, may have medicinal applications in the treatment of ulcers and intestinal infections [40]. However, the absorption into the blood system and bioavailability to body tissues both depend strongly on the molecular size of the procyanidin polymers [26]. In the gastro-intestinal tract, procyanidin monomers, dimers, and trimers are absorbed into the blood system to a much larger extent than larger oligomers and polymers [37, 43]. While the Cornelian cherries and Laurel cherries tested in this study show high degrees of polymerization, the Sour cherry procyanidins, which were present at a significant concentration $(0.3 \mathrm{~g} / 100 \mathrm{~g} \mathrm{DW})$, had an average polymer length slightly lower than 4 , indicating relative high levels of these better absorbable short-chain procyanidin species. In plant materials, the lower molecular weight procyanidins are usually present at relatively low concentrations, as compared to the larger-sized oligomers and polymers [23, 53]. For instance, the degree of polymerization in apple skin is 12.5 and 11.3 for the apple pulp [28]. In grape seed it is about 30 [63, 64], in the Laurel cherries about 45 and in the Cornelian cherries about 63 (Table 4). Therefore, this study has identified Sour cherries as being an exceptional source of short-chain procyanidins and this finding deserves further attention regarding health beneficial properties. 
The DP value is one of the most important properties in fruits and vegetables since antioxidant activity has been shown to depend on the DP values $[29,32]$. The results of our study indicated that cornelian cherry sample which had the highest DP value also showed highest antioxidant activities according to ABTS, CUPRAC, and FRAP methods (Table 1). Antioxidant activities of grape seed procyanidins are positively related to their degree of polymerization: from high to low in the order of polymer, oligomer, and monomer [49, 63]. According to Arteel and Sies [6], long-chain procyanidins are better scavengers than short-chain procyanidins. Similarly, the antioxidant activity of procyanidin oligomers was found to increase significantly with the degree of polymerization in chocolate [18]. However, according to Ndhlala et al. [48], fruits with high degree of polymerization should present lower antioxidant activity.

It has been reported that flavanols and procyanidin oligomers have a number of antioxidative properties and can provide protection against the oxidation of human low-density lipoprotein [41, 52]. They have been reported to exhibit several health beneficial effects by acting as antioxidant, anticarcinogen, cardiopreventive, antimicrobial, anti-viral, and neuro-protective agents [5]. Inhibitory effects of flavanols and procyanidin oligomers on free radical-induced erythrocyte hemolysis were also shown by Zhu et al. [72]. Even though it was reported that the antioxidant potential of procyanidins is affected in part by oligomer chain length $[6,41,44]$, the exact effect and importance of chain length and configuration of procyanidins remain unclear.

The degree of polymerization is also important for the absorption and bioavailability characteristics of procyanidin polymers [26]. It has been reported that procyanidin monomers, dimers, and trimers can be absorbed, but higher oligomers and polymers are poorly absorbed [37]. Recent studies suggest that only the low molecular weight oligomers (polymerization degree up to 3) might be absorbed in the gastrointestinal tract [43]. Considering that the polymeric procyanidins are not depolymerized in the stomach, food material containing procyanidins with a low DP value may be of particular interest [25]. Sour cherry samples in our study, which was found to have a DP value around 3 is therefore interesting for its more bioavailable procyanidin oligomers. And, taking into account the information that the lower molecular weight procyanidins are usually present in plant tissue in relatively low concentrations compared to that of larger oligomers and polymers [23, 53], sour cherry samples deserve particular attention.

Short-chain procyanidins may occur in several coupling configurations (A and B types), each of which may have different bio-activities [5]. Further research should determine which procyanidin type is predominantly present in Sour cherry fruits, and it should be tested if these compounds are, at least partly, responsible for the bio-activities described for Sour cherry fruit extracts $[51,61]$. Such studies will allow a better understanding of the health effects observed, such as reported in studies with diabetic women [8], and could lead to an improved awareness of the importance of these fruits for consumer health.

\section{Acknowledgments}

This study was financially supported by the EU $6^{\text {th }}$ Frame FLORA project (2005-FOOD-CT-01730), and EU $7^{\text {th }}$ Frame ATHENA Project (FP7-KBBE-2009-3-245121-ATHENA). Harry Jonker is acknowledged for valuable assistance in HPLC analysis. RD Hall and R deVos thank the Centre of Biosystems Genomics (CBSG) which is part of the Netherlands Genomics Initiative, for additional funding.

\section{References}

[1] M. Antolovich, P.D. Prenzler, E. Patsalides, S. McDonald and K. Robards, Methods for testing antioxidant activity, The Analyst 127 (2002), 183-198.

[2] R. Apak, K. Guclu, M. Ozyurek and S.E. Karademir, Novel total antioxidant capacity index for dietary polyphenols and vitamins C and E, using their cupric ion reducing capability in the presence of neocuproine: CUPRAC method, Journal of Agricultural and Food Chemistry 52 (2004), 7970-7981.

[3] R. Apak, K. Guclu, B. Demirata, M. Ozyurek, S.E. Celik, B. Bektasoglu, K.I. Berker, and D. Ozyurt, Comparative evaluation of various total antioxidant capacity assays applied to phenolic compounds with the CUPRAC assay, Molecules 12 (2007), 1496-1547.

[4] M.B. Arnao, Some methodological problems in the determination of antioxidant activity using chromogen radicals: a practical case, Trends in Food Science and Technology 11 (2000), 419-421. 
[5] P.M. Aron and J.A. Kennedy, Flavan-3-ols: Nature, occurrence and biological activity, Molecular Nutrition \& Food Research 52 (2008), 79-104.

[6] G.E. Arteel and H. Sies, Protection against peroxinitrite by cocoa polyphenol oligomers, FEBS Letters 462 (1999), 167-170.

[7] I.C.W. Arts, B. van de Putte and P.C.H. Hollman, Catechin contents of foods commonly consumed in The Netherlands. Fruits, vegetables, staple foods, and processed foods, Journal of Agricultural and Food Chemistry 48 (2000), 1746-1751.

[8] A. Ataie-Jafari, S. Hosseini, F. Karimi and M. Pajouhi, Effects of sour cherry juice on blood glucose and some cardiovascular risk factors improvements in diabetic women, Nutrition \& Food Science 38 (2008), 355-360.

[9] C. Auger, N. Al-Awwadi, A. Bornet, J.M. Rouanet, F. Gasc, G. Cros and P.L. Teissedre, Catechins and procyanidins in Mediterranean diets, Food Research International 37 (2004), 233-245.

[10] I.F.F. Benzie and J.J. Strain, The ferric reducing ability of plasma (FRAP) as a measure of "antioxidant power": The FRAP assay, Analytical Biochemistry 239 (1996), 70-76.

[11] R.J. Bino, C.H.R. De Vos, M. Lieberman, R.D. Hall, A. Bovy, H.H. Jonker, Y. Tikunov, A. Lommen, S. Moco and I. Levin, The lighthyperresponsive high pigment-2 dg mutation of tomato: alterations in the fruit metabolome, New Phytologist 166 (2005), 427-438.

[12] S. Calisir and C. Aydin, Some physico-mechanic properties of cherry laurel (Prunus lauracerasus L.) fruits, Journal of Food Engineering 65 (2004), 145-150.

[13] E. Capanoglu, J. Beekwilder, D. Boyacioglu, R.D. Hall and C.H.R. De Vos, Changes in antioxidants and metabolite profiles during production of tomato paste, Journal of Agricultural and Food Chemistry 56 (2008), 964-973.

[14] E. Capanoglu, J. Beekwilder, D. Boyacioglu, C.H.R. De Vos and R.H. Hall, The effect of industrial food processing on potentially health-beneficial tomato antioxidants, Critical Reviews in Food Science and Nutrition 50 (2010), 919-930.

[15] S. Celik, I. Bakirci and I.G. Suat, Physicochemical and organoleptic properties of yogurt with cornelian cherry paste, International Journal of Food Properties 9 (2006), 401-408.

[16] Y.-H. Chu, C.-L. Chang and H.-F. Hsu, Flavonoid content of several vegetables and their antioxidant activity, Journal of the Science of Food and Agriculture 80 (2000), 561-566.

[17] R. Corder, W. Mullen, N.Q. Khan, S.C. Marks, E.G. Wood, M.J. Carrier and A. Crozier, Oenology: Red wine procyanidins and vascular health, Nature 444 (2006), 566-567.

[18] C. Counet and S. Collin, Effect of the number of flavanol units on the antioxidant activity of procyanidin fractions isolated from chocolate, Journal of Agricultural and Food Chemistry 51 (2003), 6816-6822.

[19] F. Demir and I.H. Kalyoncu, Some nutritional, pomological and physical properties of cornelian cherry (Cornus mas L.), Journal of Food Engineering 60 (2003), 335-341.

[20] S. Deprez, I. Mila, J.F. Huneau, D. Tome and A. Scalbert, Transport of proanthocyanidin dimer, trimer, and polymer across monolayers of human intestinal epithelial Caco-2 cells, Antioxidant Redox Signaling 3 (2001), 957-967.

[21] V. Dewanto, X. Wu, K.K. Adom and R.H. Liu, Thermal Processing Enhances the Nutritional Value of Tomatoes by Increasing Total Antioxidant Activity, Journal of Agricultural and Food Chemistry 50 (2002), 3010-3014.

[22] S.D. Doyuran and M. Gultekin, Fruit juice sector in Turkey, Food Engineering Journal 13 (2000), 35-39.

[23] L.Y. Foo and L.J. Porter, The phytochemistry of proanthocyanidin polymers, Phytochemistry 19 (1980), 1747-1754.

[24] B. Goncalves, A.K. Landbo, D. Knudsen, A.P. Silva, J. Moutinho-Pereira, E. Rosa and A.S. Meyer, Effect of ripeness and postharvest storage on the phenolic profiles of cherries (Prunus avium L.), Journal of Agricultural and Food Chemistry 52 (2004), 523-530.

[25] S. Gonzales-Manzano, C. Santos-Buelga, J.J. Perez-Alonso, J.C. Rivas-Gonzalo and M.T. Escribano-Bailon, Characterization of the mean degree of polymerization of proanthocyanidins in red wines using Liquid Chromatography-Mass Spectrometry (LC-MS), Journal of Agricultural and Food Chemistry 54 (2006), 4326-4332.

[26] L. Gu, S.E. House, L. Rooney and R.L. Prior, Sorghum bran in the diet dose dependently increased the excretion of catechins and microbial-derived phenolic acids in female rats, Journal of Agricultural and Food Chemistry 55 (2007), 5326-5334.

[27] R. Guendez, S. Kallithraka, D.P. Makris and P. Kefalas, Determination of low molecular weight polyphenolic constituents in grape (Vitis vinifera sp.) seed extracts: Correlation with antiradical activity, Food Chemistry 89 (2005), 1-9.

[28] S. Guyot, T. Doco, J.M. Souquet, M. Moutounet and J.F. Drilleau, Characterization of highly polymerized procyanidins in Cider apple (Malus sylvestris var. Kermerrien) skin and pulp, Phytochemistry 44 (1997), 351-357.

[29] A.E. Hagerman, K.M. Riedl, G.A. Jones, K.N. Sovik, N.T. Ritchard, P.W. Hartzfeld and T.L. Riechel, High molecular weight plant polyphenolics (tannins) as biological antioxidants, Journal of Agricultural and Food Chemistry 46 (1998), 1887-1892.

[30] R.A. Jacob, G.M. Spinozzi, V.A. Simon, D.S. Kelley, R.L. Prior, B. Hess-Pierce and A.A. Kader, Consumption of cherries lowers plasma urate in healthy women, The Journal of Nutrition 133 (2003), 1826-1829.

[31] B. Jayaprakasam, S.K. Vareed, L.K. Olson and M.G. Nair, Insulin secretion by bioactive anthocyanins and anthocyanidins present in fruits, Journal of Agricultural and Food Chemistry 53 (2005), 28-31.

[32] M. Jerez, A. Selga, J. Sineiro, J.L. Torres and M.J. Nunez, A comparison between bark extracts from Pinus pinaster and Pinus radiata: Antioxidant activity and procyanidin composition, Food Chemistry 100 (2007), 439-444.

[33] S.Y. Kang, N.P. Seeram, M.G. Nair and L.D. Bourquin, Tart cherry anthocyanins inhibit tumor development in mice and reduce proliferation of human colon cancer cell, Cancer Letters 194 (2003), 13-19. 
[34] A. Kaya and O. Aydin, Experimental investigation of drying kinetics of Cherry laurel, Journal of Food Process Engineering 31 (2008), 398-412.

[35] J.A. Kennedy and G.P. Jones, Analysis of proanthocyanidin cleavage products following acid-catalysis in the presence of excess phloroglucinol, Journal of Agricultural and Food Chemistry 49 (2001), 1740-1746.

[36] J.A. Kennedy, M.A. Matthews and A.L. Waterhouse, Changes in grape seed polyphenols during fruit ripening, Phytochemistry 55 (2000), $77-85$.

[37] R.C. Khanal, L.R. Howard and R.L. Prior, Procyanidin content of grape seed and pomace, and total anthocyanin content of grape pomace as affected by extrusion processing, Journal of Food Science 74 (2009), 174-182.

[38] D.O. Kim, H.J. Heo, Y.J. Kim, H.S. Yang and C.Y. Lee, Sweet and sour cherry phenolics and their protective effects on neuronal cells, Journal of Agricultural and Food Chemistry 53 (2005), 9921-9927.

[39] S. Kolayli, M. Kucuk, C. Duran, F. Candan and B. Dincer, Chemical and antioxidant properties of Laurocerasus officinalis roem. (cherry laurel) fruit grown in the black sea region, Journal of Agricultural and Food Chemistry 51 (2003), 7489-7494.

[40] C.M. Liyana-Pathirana, F. Shahidi and C. Alasalvar, Antioxidant activity of cherry laurel fruit (Laurocerasus officinalis Roem.) and its concentrated juice, Food Chemistry 99 (2006), 121-128.

[41] S.B. Lotito, L. Actis-Goretta, L. Renart, M. Caligiuri, D. Rein, H.H. Schmitz, F.M. Steinberg, C.L. Keen and C.G. Fraga, Influence of oligomer chain length on the antioxidant activity of procyanidins, Biochemistry \& Biophysics Research Community 276 (2000), 945-951.

[42] T.L. Lunder, Catechins of green tea: antioxidant activity, in: Phenolic Compounds in Food and Their Effects on Health II, M.T. Huang, C.T. Ho and C.Y. Lee, eds., American Chemical Society Inc., Washington, DC, 1992, pp. 114-120.

[43] C. Manach, G. Williamson, C. Morand, A. Scalbert and C. Remesy, Bioavailability and bioefficacy of polyphenols in humans. I. Review of 97 bioavailability studies, American Journal of Clinical Nutrition 81 (2005), 230-242.

[44] T.K. Mao, J.J. Powell, J. Van de Water, C.L. Keen, H. Schmitz and M.E. Gershwin, The influence of cocoa procyanidins on the transcription of interleukin-2 in peripheral blood mononuclear cells, Journal of Immunotherapy 15 (1999), 23-29.

[45] T.K. Mao, J.J. Powell, J. Van de Water, C.L. Keen, H.H. Schmitz, J.F. Hammerstone and M.E. Gershwin, The effect of cocoa procyanidins on the transcription and secretion of interleukin-1 in peripheral blood mononuclear cells, Life Science 66 (2000), 1377-1386.

[46] K.B. Miller, W.J. Hurst, N. Flannigan, B. Ou, C.Y. Lee, N. Smith and D.A. Stuart, Survey of commercially available chocolate- and cocoa-containing products in the United States. Comparison of flavan-3-ol content with nonfat cocoa solids, total polyphenols, and percent cacao, Journal of Agricultural and Food Chemistry 57 (2009), 9169-9180.

[47] N.J. Miller and C.A. Rice-Evans, Factors influencing the antioxidant activity determined by the ABTS ${ }^{+}$radical cation assay, Free Radical Research 26 (1997), 195-199.

[48] A.R. Ndhlala, C.H. Mupure, K. Chitindingu, M.A.N. Benhura and M. Muchuweti, Antioxidant potentials and degrees of polymerization of six wild fruits, Scientific Research and Essay 1 (2006), 87-92.

[49] N. Osakabe, A. Yasuda, M. Natsume, T. Takizawa, J. Terao and K. Kondo, Catechins and their oligomers linked by C4-C8 bonds are major cacao polyphenols and protect low-density lipoprotein from oxidation in vitro, Experimental Biology and Medicine 227 (2002), 51-56.

[50] A.S. Pannala, T.S. Chan, P.J. O’Brien and C.A. Rice-Evans, Flavonoid B-ring chemistry and antioxidant activity: Fast reaction kinetics, Biochemical and Biophysical Research Communications 282 (2001), 1161-1168.

[51] N. Papp, B. Szilva, L. Abranko, T. Szabo, P. Pfeiffer, Z. Szabo, J. Nyeki, S. Ercisli, E. Stefanovits-Banyail and A. Hegedus, Main quality attributes and antioxidants in Hungarian sour cherries: identification of genotypes with enhanced functional properties, International Journal of Food Science and Technology 45 (2010), 395-402.

[52] D.A. Pearson, H.H. Schmitz, S.A. Lazarus and C.L. Keen, Inhibition of in vitro low-density lipoprotein oxidation by oligomeric procyanidins present in chocolate and cocoa, in: Methods in Enzymology, L. Packer, ed., Academic Press, New York, 2001, pp. 350-360.

[53] R.L. Prior and L. Gu, Occurrence and biological significance of proanthocyanidins in the American diet, Phytochemistry 66 (2005), 2264-2280.

[54] A. Raffo, C. Leopardi, V. Fogliano, P. Ambrosino, M. Salucci, L. Gennaro, R. Bugianesi, F. Giufridda and G. Quaglia, Nutritional value of cherry tomatoes (Lycopersicon esculentum cv. Naomi F1) harvested at different ripening stages, Journal of Agricultural and Food Chemistry 50 (2002), 6550-6556.

[55] C. Rice-Evans and L. Packer, Flavonoids in Health and Disease, Dekker, New York, 1997.

[56] A. Saric, S. Sobočanec, T. Balog, B. Kušić, V. Šverko, V. Dragović-Uzelac, B. Levaj, Z. Čosić, Z.M. Šafranko and T. Marotti, Improved antioxidant and anti-inflammatory potential in mice consuming sour cherry juice (Prunus Cerasus cv. Maraska), Plant Foods for Human Nutrition 64 (2009), 231-237.

[57] D.D. Schramm, J.F. Wang, R.R. Holt, J.L. Ensunsa, J.L. Gonsalves, S.A. Lazarus, H.H. Schmitz, J.B. German and C.L. Keen, Chocolate procyanidins decrease the leukotrieneprostacyclin ratio in humans and human aortic endothelial cells, Amercian Journal of Clinical Nutrition 73 (2001), 36-40.

[58] N.P. Seeram, L.D. Bourquin and M.G. Nair, Degradation products of cyanidin glycosides from tart cherries and their bioactivities, Journal of Agricultural and Food Chemistry 49 (2001), 4924-4929.

[59] J. Shi, J. Yu, J.E. Pohorly and Y. Kakuda, Polyphenolics in grape seeds-biochemistry and functionality, Journal of Medicinal Food 6 (2003), 291-299. 
[60] P. Simonetti, S. Ciappellano, C. Gardana, L. Bramati and P. Pietta, Procyanidins from Vitis vinifera seeds: In vivo effects on oxidative stress, Journal of Agricultural and Food Chemistry 50 (2002), 6217-6221.

[61] V. Simunic, S. Kovac, D. Gaso-Sokac, W. Pfannhauser and M. Murkovic, Determination of anthocyanins in four Croatian cultivars of sour cherries (Prunus cerasus). European Food Research and Technology 220 (2005), 575-578.

[62] G.A. Spanos and R.E. Wroldstad, Influence of processing and storage on the phenolic composition of thompson seedless grape juice, Journal of Agricultural and Food Chemistry 38 (1990), 1565-1571.

[63] I. Spranger, B. Sun, A.M. Mateus, V. de Freitas and J.M. Ricardo-da-Silva, Chemical characterization and antioxidant activities of oligomeric and polymeric procyanidin fractions from grape seeds, Food Chemistry 108 (2008), 519-532.

[64] B.S. Sun, M.C. Leandro, J.M. Ricardo-da-Silva and M.I. Spranger, Separation of grape and wine proanthocyanidins according to their degree of polymerization, Journal of Agricultural and Food Chemistry 46 (1998), 1390-1396.

[65] S. Tural and I. Koca, Physico-chemical and antioxidant properties of cornelian cherry fruits (Cornus mas L.) grown in Turkey, Scientia Horticulturae 116 (2008), 362-366.

[66] S.K. Vareed, M.K. Reddy, R.E. Schutzki and M.G. Nair, Anthocyanins in Cornus alternifolia, Cornus controversa, Cornus kousa and Cornus florida fruits with health benefits, Life Sciences 78 (2006), 777-784.

[67] S.V. Verstraeten, J.F. Hammerstone, C.L. Keen, C.G. Fraga and P.I. Oteiza, Antioxidant and membrane effects of procyanidin dimers and trimers isolated from peanut and cocoa, Journal of Agricultural and Food Chemistry 53 (2005), 5041-5048.

[68] F. Virgili, D. Kim and L. Packer, Procyanidins extracted from pine bark protect R-tocopherol in ECV 304 endothelial cells challenged by activated RAW 264.7 macrophages: Role of nitric oxide and peroxynitrate, FEBS Letters 431 (1998), 315-318.

[69] N.V. Yanishlieva-Maslarova and I.M. Heinonen, Sources of natural antioxidants: vegetables, fruits, herbs, spices and teas, in: Antioxidants in Food, J. Pokorny, N. Yanishlieva and M. Gordon, eds., Woodhead Publishing, Ltd., New York, 2001, pp. 34-60.

[70] K.U. Yilmaz, S. Ercisli, Y. Zengin, M. Sengul and E. Yasa-Kafkas, Preliminary characterisation of cornelian cherry (Cornus mas L.) genotypes for their physico-chemical properties, Food Chemistry 114 (2009), 408-412.

[71] Q.Y. Zhu, J.F. Hammerstone, S.A. Lazarus, H.H. Schmitz, C.L. Keen, Stabilizing Effect of Ascorbic Acid on Flavan-3-ols and Dimeric Procyanidins from Cocoa, Journal of Agricultural and Food Chemistry 51 (2003), 828-833.

[72] Q.Y. Zhu, R.R. Holt, S.A. Lazarus, T.J. Orozco and C.L. Keen, Inhibitory effects of cocoa flavanols and procyanidin oligomers on free radical-induced erythrocyte hemolysis, Experimental Biology and Medicine 227 (2002), 321-329. 